\title{
Leksell Gamma Knife radiosurgery of the jugulotympanic glomus tumor: long-term results
}

\author{
Clinical article
}

\author{
Roman Liscak, M.D., ${ }^{1}$ Dusan Urgosik, M.D., ${ }^{1}$ Tomas ChytKa, M.D., ${ }^{1}$ \\ Gabriela Simonova, M.D., ${ }^{1}$ Josef Novotny JR., Ph.D., ${ }^{2}$ Josef Vymazal, M.D., ${ }^{3}$ \\ Khumar Guseynova, M.D., ${ }^{1}$ and Vilibald Vladyka, M.D. ${ }^{1}$ \\ Departments of ${ }^{1}$ Stereotactic and Radiation Neurosurgery, ${ }^{2}$ Medical Physics, and ${ }^{3}$ Radiology, Na Homolce \\ Hospital, Prague, Czech Republic
}

\begin{abstract}
Object. Glomus tumors usually display indolent behavior, and the effectiveness of radiation in stopping their growth can be assessed after long-term follow-up. Currently only midterm results of radiosurgery are available, so the authors included patients treated by Gamma Knife at least 10 years ago in this study to obtain a perspective of long-term results.

Methods. During the period from 1992 to 2003, the Gamma Knife was used to treat 46 patients with glomus tumors. The age of the patients ranged from 21 to 79 years (median 56 years). Gamma Knife radiosurgery was the primary treatment in 17 patients (37\%). Open surgery preceded radiosurgery in $46 \%$ of cases, embolization in $17 \%$, and fractionated radiotherapy in $4 \%$. The volume of the tumor ranged from 0.2 to $24.3 \mathrm{~cm}^{3}$ (median $\left.3.6 \mathrm{~cm}^{3}\right)$. The minimal dose to the tumor margin ranged between 10 and $30 \mathrm{~Gy}$ (median $20 \mathrm{~Gy}$ ).

Results. One patient was lost for follow-up after radiosurgery. Clinical follow-up was available in 45 patients and 44 patients were followed with MRI in a follow-up period that ranged from 12 to 217 months (median 118 months). Neurological deficits improved in $19(42 \%)$ of 45 patients and deteriorated in 2 patients (4\%). Tumor size decreased in $34(77 \%)$ of 44 patients with imaging follow-up, while an increase in volume was observed in 1 patient $(2 \%) 182$ months after radiosurgery and Gamma Knife treatment was repeated. One patient underwent another Gamma Knife treatment for secondary induced meningioma close to the glomus tumor 98 months after initial radiosurgical treatment. Seven patients died 22-96 months after radiosurgery (median 48 months), all for unrelated reasons.

Conclusions. Radiosurgery has proved to be a safe treatment with a low morbidity rate and a reliable long-term antiproliferative effect.

(http://thejns.org/doi/abs/10.3171/2014.7.GKS14923)
\end{abstract}

\section{KeY Words • stereotactic radiosurgery • Gamma Knife • complications • glomus jugulare tumor $\quad$ long-term results}

$\mathrm{G}$ LOMUS tumors are not common, and their incidence is estimated to be 1 in 1 million people. ${ }^{21}$ Although this tumor can appear at any age, it is usually found in individuals between 50 and 60 years of age and is 4-6 times more frequent in women than in men. ${ }^{10,11,22}$ These tumors are usually benign, with malignant forms being found in about $3 \%$ of cases. ${ }^{8,11}$

While CT is superior to MRI in visualizing the bone destruction caused by the tumor, MRI is better at showing the intracranial involvement and the extension under the skull base. In uncertain cases or in cases involving small tumors, a decisive finding provided given by cerebral angiography. Vascularity on digital subtraction angiography is typical for glomus tumors and enables the correct diagnosis to be made without histological examination. ${ }^{14}$

Tumors originating in the paraganglia grow slowly, and to date only midterm results have been pub- lished. . $^{1,4,6-8,13,18,20,23,24}$ Because a verification of the effectiveness of radiosurgery from a longer-term perspective is needed, we have focused on the results of the treatment in cases in which 10 years or more has elapsed since the treatment.

\section{Methods}

The Leksell Gamma Knife (Elekta AB) was used to treat 46 patients with glomus tumor (40 patients had glomus jugulare tumors and 6 patients glomus tympanicum tumors) between 1992 and 2003. The age of the 33 female and 13 male patients ranged between 21 and 79 years (median 56 years). Clinical symptoms before radiosurgery are summarized in Table 1. Contribution of the previous treatment to the clinical symptoms was suspected in 21 patients $(46 \%)$, whereas in $25(54 \%)$ of the patients, the symptoms 
TABLE 1: Clinical characteristics of the 46 patients*

\begin{tabular}{lccc}
\hline & \multicolumn{3}{c}{ Clinical Symptoms } \\
\cline { 2 - 4 } \multicolumn{1}{c}{ Symptom } & $\begin{array}{c}\text { No. wl } \\
\text { SRS (\%) }\end{array}$ & $\begin{array}{c}\text { Median Time Course } \\
\text { Improvement } \\
\text { After SRS }\end{array}$ & $\begin{array}{c}\text { When Improvement } \\
\text { Was Observed (range) }\end{array}$ \\
\hline hearing loss & $36(78)$ & 0 & $30(6-60)$ \\
tinnitus & $28(61)$ & 8 & $18(12-24)$ \\
headache & $20(43)$ & 2 & $27(24-36)$ \\
dizziness-vertigo & $17(37)$ & 3 & $24(24-24)$ \\
neuropathy & & & $24(12-180)$ \\
CN VII & $14(30)$ & 3 & \\
CN IX-X & $10(22)$ & 6 & \\
CN V & $2(4)$ & 0 & \\
CN VI & $2(4)$ & 0 & \\
CN XII & $1(2)$ & 0 & \\
\hline
\end{tabular}

* $\mathrm{CN}=$ cranial nerve; SRS = stereotactic radiosurgery.

$\dagger$ Time course represented in months.

resulted just from the tumor itself. Intracranial spread of the tumor was found in 15 patients. The time interval between the appearance of the first symptoms and the diagnosis ranged from 1 month to 19 years (median 12 months). Twenty-one patients had previously undergone open surgery $(46 \%)$. Embolization of the tumor was conducted in 8 patients (17\%) and fractionated radiotherapy was used in 2 patients (4\%). Gamma Knife radiosurgery was the primary treatment in 17 patients $(37 \%)$. In cases in which surgery was not performed and no histological diagnosis was obtained, the diagnosis was confirmed by CT, MRI, and clinical symptoms, as well as by the demonstration of typical vascularization on angiography.

The volume of the tumor ranged from 0.2 to $24.3 \mathrm{~cm}^{3}$ (median $3.6 \mathrm{~cm}^{3}$ ). Radiosurgery was performed using the Gamma Knife. The minimum dose to the tumor margin ranged from 10 to $30 \mathrm{~Gy}$ (median $20 \mathrm{~Gy}$ ), and maximum dose ranged from 20 to 60 Gy (median 40 Gy).

All statistical analyses of data were performed using the statistical software package IBM SPSS Statistics Version 20. Kaplan-Meier curves were used to plot the fraction of patients with tumor volume decrease over time after radiosurgery (Fig. 1) and the significance of the margin dose to the tumor decrease (Fig. 2) was tested. Three tests were used to evaluate statistical significance: log-rank, Breslow, and Tarone-Ware. Significance was set at $\mathrm{p}<0.05$.

\section{Results}

One patient was lost for follow-up after radiosurgery. Clinical follow-up was available in 45 patients, and 44 patients were followed with MRI, in a follow-up period that ranged from 12 to 217 months (median 118 months). Neurological deficit improved in 19 (42\%) of 45 patients 6-180 months after the radiosurgery (median 24 months) and deteriorated in 2 patients (4\%). Symptoms that improved are listed in Table 1. Ten of 19 patients with clinical improvement had treatment before undergoing Gamma Knife radiosurgery (open surgery in 5 and embolization

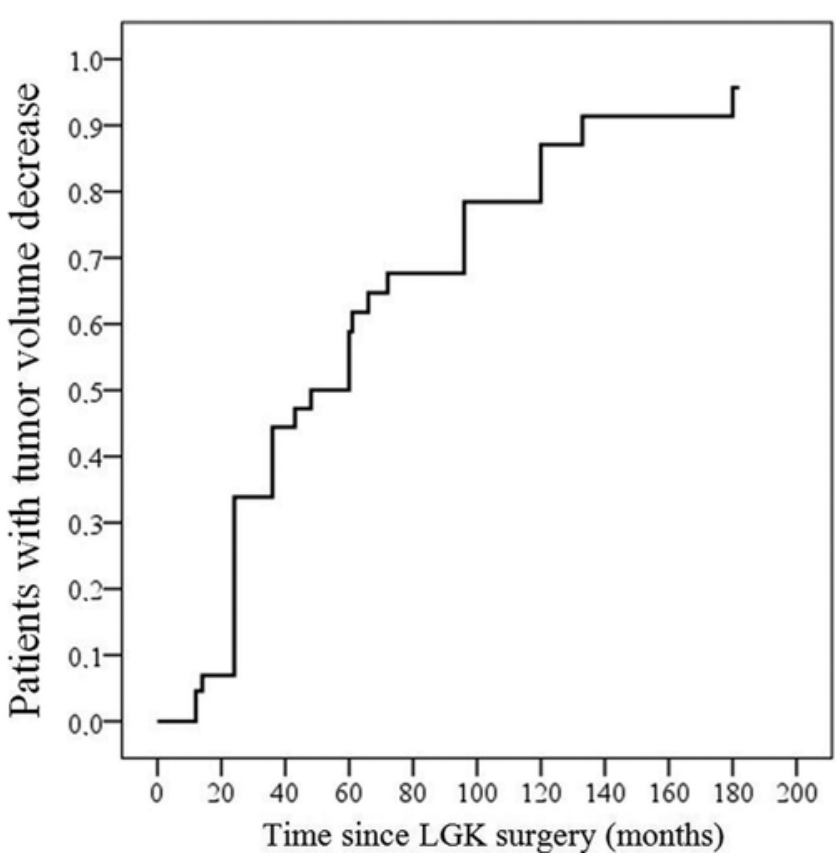

FIG. 1. Kaplan-Meier curve showing patients with tumor volume decrease as a function of time since Leksell Gamma Knife (LGK) surgery.

in 5); therefore, recovery from previous treatment-related morbidity can contribute to clinical improvement in these patients. A new neurological deficit (tinnitus) was observed in one patient 48 months after the treatment, and a facial nerve palsy associated with tumor recurrence occurred 182 months after initial radiosurgery in another patient. Seven patients died 22-96 months after radiosurgery (median 48 months), and all deaths were unrelated to the radiosurgical treatment (heart failure, ictus, and cancer).

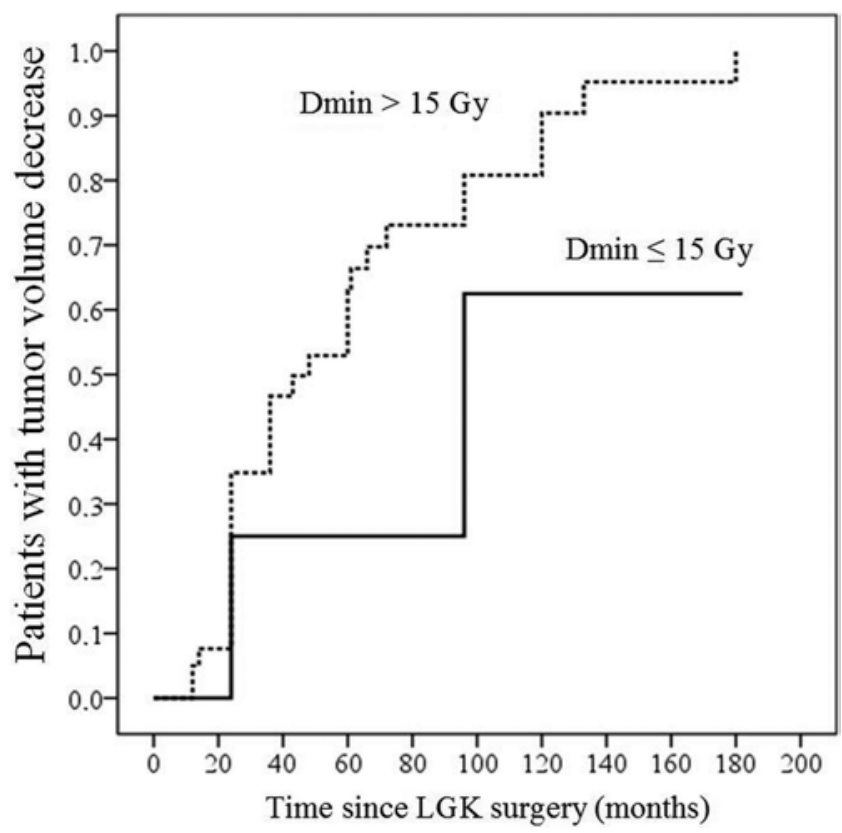

FIG. 2. Kaplan-Meier curves showing patients with tumor volume decrease as a function of time since Gamma Knife surgery and margin dose. Dmin = minimum radiation dose . 
The size of the tumor decreased in 34 (77\%) of 44 patients with imaging follow-up. The decrease in size ranged from $10 \%$ of the original volume to complete regression (median decrease, $50 \%$ of the original volume) (Fig. 3). Although different dynamics in tumor volume response based on the minimum tumor dose were observed, these were not statistically significant (Fig. 2). However, only 4 patients were given a margin dose $\leq 15 \mathrm{~Gy}$.

An increase in tumor volume was observed in 1 patient (2\%) 182 months after radiosurgery, and Gamma Knife treatment was repeated (tumor volume for the first treatment was $6.8 \mathrm{~cm}^{3}$ and the margin dose was $14 \mathrm{~Gy}$; increased volume was $10.7 \mathrm{~cm}^{3}$, and the dose for repeat treatment was 15 Gy). Thirty-six months after repeat treatment, regression of the reirradiated tumor to a volume of $9.9 \mathrm{~cm}^{3}$ was observed.

Control angiography after radiosurgery was performed in 5 patients. In 3 patients a regression of pathological vascularization was observed 12,35 , and 36 months after radiosurgery. In the remaining 2 patients, there was no change in tumor vascularity 27 and 70 months after Gamma Knife treatment.

One patient had an intracerebral arteriovenous malformation in addition to the glomus tumor. The arteriovenous malformation was treated by Gamma Knife ra- diosurgery and complete obliteration was achieved. Tumor duplicity in the head was observed in 5 patients; in 2 patients pituitary adenoma was detected and 1 of them was treated with the Gamma Knife for adenoma growth 152 months after the initial treatment of the glomus tumor, while another patient, with a microadenoma and no growth, was monitored for 10 years. In 3 patients an ipsilateral meningioma was diagnosed. Meningiomas diagnosed in 2 patients-in the temporal region 13 years after initial radiosurgery in one and in the parietal region 10 years after initial radiosurgery in the other-are only being followed up. We cannot exclude the possibility that meningioma in the third patient was induced by radiosurgical treatment of the glomus tumor, because it was detected in the posterior fossa, close (at a distance of 2 $\mathrm{cm})$ to the glomus tumor. This patient underwent Gamma Knife treatment for a meningioma close to the glomus tumor 98 months after initial radiosurgery. We have retrospectively measured the maximum dose at the site of the new meningioma during the radiosurgery for glomus tumor, which was $3.5 \mathrm{~Gy}$.

\section{Discussion}

The natural course of the nonhereditary form of the

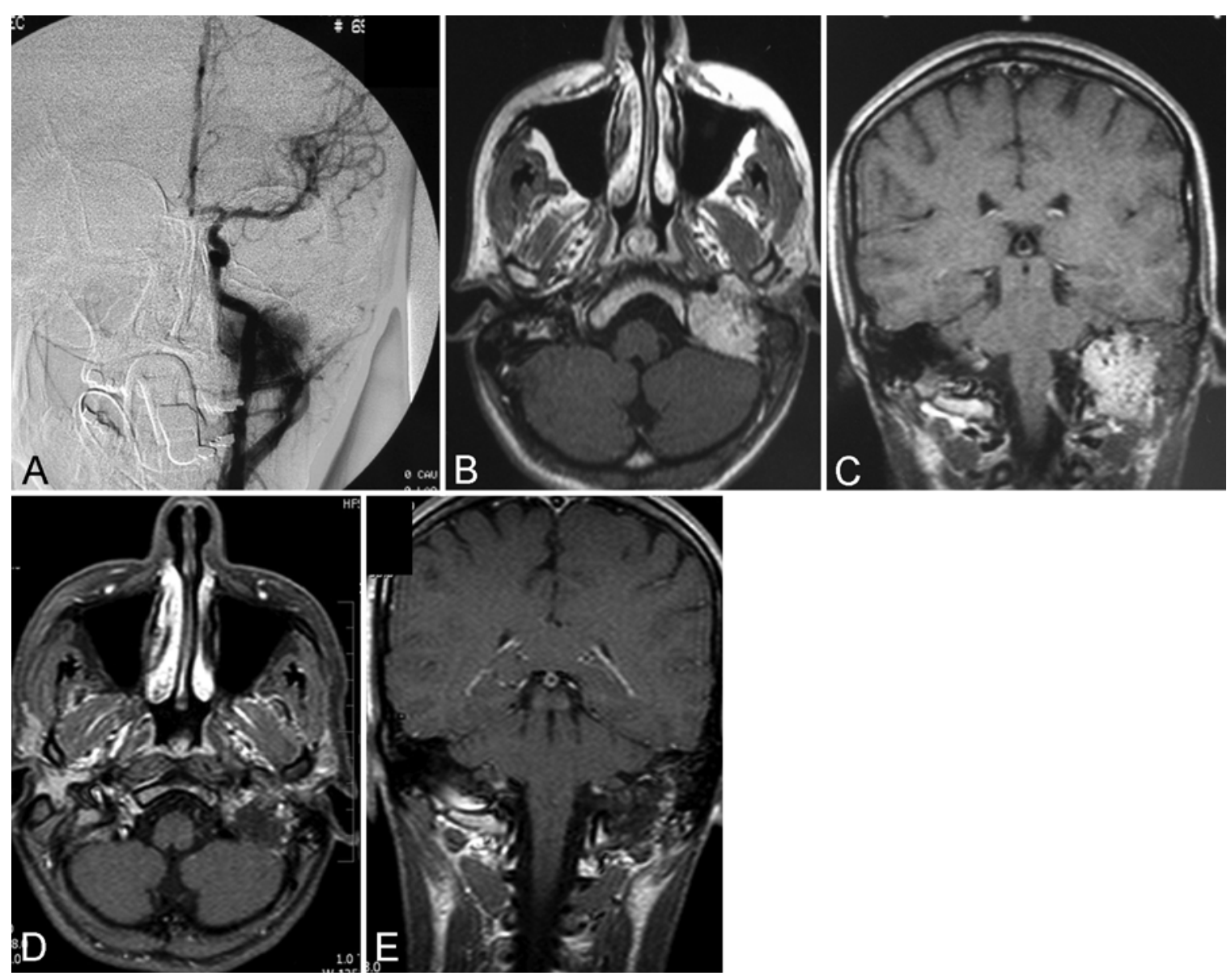

FIG. 3. Studies obtained in a 29 -year-old woman. A: Despite 6 sessions of embolization the vascularization of the tumor remained unchanged. B and C: The volume of the tumor was $13.4 \mathrm{~cm}^{3}$, and $22 \mathrm{~Gy}$ to $50 \%$ isodose was applied. D and E: MR images 10 years after radiosurgery show a decreased volume to $5.6 \mathrm{~cm}^{3}$ and significantly reduced contrast enhancement. 
glomus jugulare tumor often shows indolent behavior. Van der Mey et al. ${ }^{22}$ compared a group of patients who received no treatment and a group that received surgical treatment and found no significant difference except for the morbidity consequences after surgery. Therefore, the authors recommended observation for tumors of the glomus jugulare that show no progressive neuropathy of the cranial nerves or any intracranial propagation. This opinion has been vindicated by the finding that after surgical removal of the tumor more than $15 \%$ of patients will not be able to enjoy the kind of lifestyle they had before surgery. ${ }^{10}$ When radiosurgery is available, waiting and postponing the treatment is less advantageous. Radiosurgery represents a minimal burden or risk to the patient, especially when applied to a small tumor volume. .,9,15,16 Waiting for tumor enlargement may mean that the right time for treatment is missed, because a large tumor volume can be a contraindication for radiosurgery, or the conditions for this treatment may become more complicated.

Radiosurgery of glomus jugulare tumors could be considered for all patients in whom the tumor volume and its localization make such a treatment option possible. However, in the published series, it is not possible to evaluate the long-term effectiveness of radiosurgery on slowly growing tumors from paraganglia because only short-term or midterm follow-up has been reported to date (Table 2). ${ }^{1,3-7,9,13,15-20,23,24}$

The largest published series represents a multicenter study involving the treatment of 132 patients. ${ }^{20}$ The authors of this retrospective study of 8 Gamma Knife centers assessed 132 patients in a median follow-up period of 50.5 months. The median margin dose was $15 \mathrm{~Gy}$. Tumor control was achieved in $93 \%$ of patients, and actuarial tumor control was $88 \%$ at 5 years postradiosurgery. An improvement of neurological symptoms was seen in $11 \%$ of patients; tinnitus improved in $49 \%$ of patients who reported it at presentation. New or progressive cranial nerve deficits were observed in $11 \%$ of patients. Other published series have not exceeded the total number of patients in this multicenter study, and the results are similar-i.e., during the midterm follow-up, the safety of radiosurgery has been confirmed by the low risk of complications and the rate of tumor control of between $73 \%$ and $100 \%$. $^{1,3-7}$, 9,13,15-20,23,24 Guss and colleagues, ${ }^{12}$ in a meta-analysis of 19 studies, including data from 335 patients with glomus jugulare tumors, found that $97 \%$ of patients achieved tumor control, with 8 studies reporting a mean or median follow-up duration of more than 36 months. In these studies, clinical control and tumor control were achieved in 95\% and $96 \%$ of patients, respectively. High rates of tumor control and clinical control have been achieved using Gamma Knife, LINAC, and CyberKnife technologies.

As in open neurosurgery, the necessary follow-up interval for evaluation of radiosurgical results should be more than 5 years. Glomus tumors are considered relatively radioresistant, and histological changes after radiotherapy comprise degenerative fibrosis in the connective stromal tissue and thrombosis of small vessels. ${ }^{2}$ Therefore, the opinion has been expressed that the effect of the radiotherapy of this tumor is its devitalization caused by the radiation-induced obliteration of the pathological vessels and that radiotherapy itself has no effect on the tumor cells. ${ }^{8}$ However, the angiographically proven changes in the vascularization of the tumor have not been consistently observed, despite the positive clinical effect of the treatment. ${ }^{16}$ The disappearance of pathological vessels is not the goal of radiosurgery. The aim of radiosurgery is to stop the tumor's growth without the morbidity associated with surgery. In some patients embolization was achieved before radiosurgery, but embolization before radiosurgical treatment is not indicated (Fig. 3). While embolization may reduce intraoperative blood loss in patients who will undergo subsequent open surgery, it is unnecessary before radiosurgery, and adding to the risks of morbidity from other therapeutic methods is undesirable.

The morbidity associated with radiosurgery in our series and also in other reported series ${ }^{1,3-7,9,13,15-20,23,24}$ was low, nondisabling, and usually temporary. There was no mortality associated with treatment of the glomus tumor itself. We cannot exclude induced meningioma in one of our patients 15 years after initial treatment, but the meningioma was treated by repeat Gamma Knife radiosurgery without any additional morbidity. We observed no malignant tumor in the region of the head in any of treated

TABLE 2: Characteristics of radiosurgical studies*

\begin{tabular}{|c|c|c|c|c|c|c|}
\hline Authors \& Year & $\begin{array}{c}\text { No. of } \\
\text { Patients }\end{array}$ & Treatment & $\begin{array}{l}\text { Margin Dose } \\
\text { (Gy) }\end{array}$ & Follow-Up (mos) & $\begin{array}{c}\text { Tumor Control } \\
\text { Rate }\end{array}$ & $\begin{array}{c}\text { Complication } \\
\text { Rate }\end{array}$ \\
\hline de Andrade et al., 2013 & 15 & LINAC & mean 14 & mean 35.4 & $100 \%$ & $7 \%$ \\
\hline Sheehan et al., 2012 & 132 & Gamma Knife & median 15 & median 50.5 & $93 \%$ & $15 \%$ \\
\hline Lee et al., 2011 & 14 & Gamma Knife & mean 13.7 & median 40.3 & $100 \%$ & $7 \%$ \\
\hline Chen et al., 2010 & 15 & Gamma Knife & mean 14.6 & mean 43.2 & $80 \%$ & NS \\
\hline Genç et al., 2010 & 18 & Gamma Knife & mean 15.6 & mean 52.7 & $94.4 \%$ & $5.5 \%$ \\
\hline Ganz \& Abdelkarim, 2009 & 14 & Gamma Knife & mean 13.6 & mean 28 & $100 \%$ & $7 \%$ \\
\hline Sharma et al., 2008 & 13 & Gamma Knife & mean 16.3 & median 24 & $100 \%$ & $7.7 \%$ \\
\hline Varma et al., 2006 & 15 & Gamma Knife & median 15 & median 48 & $73 \%$ & $11.8 \%$ \\
\hline Feigl \& Horstmann, 2006 & 12 & Gamma Knife & mean 17 & mean 33 & $100 \%$ & $8.3 \%$ \\
\hline Gerosa et al., 2006 & 20 & Gamma Knife & mean 17.3 & mean 50.9 & $95 \%$ & $10 \%$ \\
\hline
\end{tabular}

* Not specified. 
patients; 2 patients died of unrelated cancer (4 years after radiosurgery for prostate gland cancer and 7 years after radiosurgery for gastrointestinal tract cancer, which had already been diagnosed before Gamma Knife treatment).

\section{Conclusions}

Radiosurgery has proved to be a safe treatment with a low morbidity rate and a reliable long-term antiproliferative effect. Treatment led to a decrease in tumor volume in $77 \%$ of the patients and neurological deficits improved in $42 \%$. Quality of life was not affected by radiosurgery in any of the patients.

\section{Disclosure}

Roman Liscak and Josef Novotny Jr. are consultants with Elekta AB.

The paper was supported by Ministry of Health, Czech Republic (Nemocnice Na Homolce, NNH, 00023884).

Author contributions to the study and manuscript preparation include the following. Conception and design: Liscak. Acquisition of data: Liscak, Urgosik, Chytka, Simonova, Guseynova, Vladyka. Analysis and interpretation of data: Liscak, Vymazal. Drafting the article: Liscak. Critically revising the article: Liscak. Reviewed submitted version of manuscript: Liscak, Urgosik, Chytka, Simonova, Novotny, Vymazal, Vladyka. Approved the final version of the manuscript on behalf of all authors: Liscak. Statistical analysis: Novotny. Administrative/technical/material support: Liscak. Study supervision: Liscak.

\section{References}

1. Chen PG, Nguyen JH, Payne SC, Sheehan JP, Hashisaki GT: Treatment of glomus jugulare tumors with gamma knife radiosurgery. Laryngoscope 120:1856-1862, 2010

2. Cole JM, Beiler D: Long-term results of treatment for glomus jugulare and glomus vagale tumors with radiotherapy. Laryngoscope 104:1461-1465, 1994

3. de Andrade EM, Brito JR, Mario SD, de Melo SM, Benabou $\mathrm{S}$ : Stereotactic radiosurgery for the treatment of Glomus Jugulare Tumors. Surg Neurol Int 4 (Suppl 6):S429-S435, 2013

4. Feigl GC, Horstmann GA: Intracranial glomus jugulare tumors: volume reduction with Gamma Knife surgery. J Neurosurg 105 Suppl:161-167, 2006

5. Foote RL, Pollock BE, Gorman DA, Schomberg PJ, Stafford SL, Link MJ, et al: Glomus jugulare tumor: tumor control and complications after stereotactic radiosurgery. Head Neck 24:332-339, 2002

6. Ganz JC, Abdelkarim K: Glomus jugulare tumours: certain clinical and radiological aspects observed following Gamma Knife radiosurgery. Acta Neurochir (Wien) 151:423-426, 2009

7. Genç A, Bicer A, Abacioglu U, Peker S, Pamir MN, Kilic T: Gamma knife radiosurgery for the treatment of glomus jugulare tumors. J Neurooncol 97:101-108, 2010

8. George B: Jugulare foramen paragangliomas. Acta Neurochir (Wien) 118:20-26, 1992

9. Gerosa M, Visca A, Rizzo P, Foroni R, Nicolato A, Bricolo A: Glomus jugulare tumors: the option of gamma knife radiosurgery. Neurosurgery 59:561-569, 2006

10. Green JD Jr, Brackmann DE, Nguyen CD, Arriaga MA, Telis- chi FF, De la Cruz A: Surgical management of previously untreated glomus jugulare tumors. Laryngoscope 104:917-921, 1994

11. Gulya AJ: The glomus tumor and its biology. Laryngoscope 103 (11 Pt 2 Suppl 60):7-15, 1993

12. Guss ZD, Batra S, Limb CJ, Li G, Sughrue ME, Redmond K, et al: Radiosurgery of glomus jugulare tumors: a meta-analysis. Int J Radiat Oncol Biol Phys 81:e497-e502, 2011

13. Lee CC, Pan DH, Wu JC, Chung WY, Wu HM, Yang HC, et al: Gamma knife radiosurgery for glomus jugulare and tympanicum. Stereotact Funct Neurosurg 89:291-298, 2011

14. Link MJ, Ebersold MJ, Morita A, Olsen KD, Quast LM: Glomus jugulare tumor, in: Kaye AH, Laws ER Jr (eds): Brain Tumors: An Encyclopedic Approach, ed 2. New York: Churchill Livingstone, 2001, pp 869-881

15. Liscák R, Vladyka V, Simonová G, Vymazal J, Janousková L: Leksell gamma knife radiosurgery of the tumor glomus jugulare and tympanicum. Stereotact Funct Neurosurg 70 (Suppl 1):152-160, 1998

16. Liscák R, Vladyka V, Wowra B, Kemeny A, Forster D, Burzaco JA, et al: Gamma Knife radiosurgery of the glomus jugulare tumour-early multicentre experience. Acta Neurochir (Wien) 141:1141-1146, 1999

17. Saringer W, Khayal H, Ertl A, Schoeggl A, Kitz K: Efficiency of gamma knife radiosurgery in the treatment of glomus jugulare tumors. Minim Invasive Neurosurg 44:141-146, 2001

18. Sharma MS, Gupta A, Kale SS, Agrawal D, Mahapatra AK, Sharma BS: Gamma knife radiosurgery for glomus jugulare tumors: therapeutic advantages of minimalism in the skull base. Neurol India 56:57-61, 2008

19. Sheehan J, Kondziolka D, Flickinger J, Lunsford LD: Gamma knife surgery for glomus jugulare tumors: an intermediate report on efficacy and safety. J Neurosurg 102 Suppl:241-246, 2005

20. Sheehan JP, Tanaka S, Link MJ, Pollock BE, Kondziolka D, Mathieu D, et al: Gamma Knife surgery for the management of glomus tumors: a multicenter study. Clinical article. J Neurosurg 117:246-254, 2012

21. Thedinger BA, Glasscock ME III, Cueva RA, Jackson CG: Postoperative radiographic evaluation after acoustic neuroma and glomus jugulare tumor removal. Laryngoscope 102:261266, 1992

22. van der Mey AGL, Frijns JH, Cornelisse CJ, Brons EN, van Dulken H, Terpstra HL, et al: Does intervention improve the natural course of glomus tumors? A series of 108 patients seen in a 32-year period. Ann Otol Rhinol Laryngol 101:635642,1992

23. van Hulsteijn LT, Corssmit EP, Coremans IE, Smit JW, Jansen JC, Dekkers OM: Regression and local control rates after radiotherapy for jugulotympanic paragangliomas: systematic review and meta-analysis. Radiother Oncol 106:161-168, 2013

24. Varma A, Nathoo N, Neyman G, Suh JH, Ross J, Park J, et al: Gamma knife radiosurgery for glomus jugulare tumors: volumetric analysis in 17 patients. Neurosurgery 59:1030-1036, 2006

Manuscript submitted April 28, 2014.

Accepted July 16, 2014.

Please include this information when citing this paper: DOI: 10.3171/2014.7.GKS14923.

Address correspondence to: Roman Liscak, M.D., Na Homolce Hospital, Roentgenova 2, Prague 150 30, Czech Republic. email: roman.liscak@homolka.cz. 